\title{
Post-treatment surveillance in colorectal cancer
}

\author{
Vaneja Velenik \\ Institute of Oncology Ljubljana, Ljubljana, Slovenia \\ Received 2 January 2010 \\ Accepted 18 January 2010 \\ Correspondence to: Assist. Prof. Vaneja Velenik, MD, PhD, Department of Radiotherapy, Institute of Oncology Ljubljana, \\ Zaloška c. 2, 1000 Ljubljana, Slovenia. Phone: +386 15879 661; Fax: +386 15879 304; E-mail: vvelenik@onko-i.si \\ Disclosure: No potential conflicts of interest were disclosed.
}

\begin{abstract}
Background. Though the post treatment surveillance of patients with colorectal cancer (CRC) treated with curative intent is common practice, its value is controversial. In the absence of conclusive clinical data, various modalities for the routine follow-up of patients with CRC have been proposed. In practice, the guidelines across countries and regions differ and are influenced by different health care policies, resource availability and doubts about effectiveness of follow-up.

Conclusions. The results of metaanalyses of available clinical trials demonstrated a survival benefit of intensified monitoring, but the questions regarding the optimal frequency of visits and the examinations to be performed remain unanswered. Furthermore, intensive monitoring of CRC survivors may be difficult to be administrated, causes discomfort and morbidity to the patient and can have serious cost-implications to the healthcare system. However, as it seems from available data, a comprehensive surveillance program does not affect the quality of patients' life. Ongoing large prospective multi-institutional randomised trials might elucidate some of the crucial questions and existing dilemmas to establish adequate surveillance strategy for CRC patients.
\end{abstract}

Key words: surveillance; colorectal cancer

\section{Introduction}

Colorectal cancer (CRC) is a significant public health problem. In Slovenia, CRC is the second most frequently diagnosed cancer in both men and women and the second leading cause of cancer death, with estimated 1,284 new cases and 682 related deaths in 2006. ${ }^{1}$ Five year relative survival in 2005 was $57.7 \%$ for colon cancer and $45.4 \%$ for rectal cancer, increasing by $16.2 \%$ and $11.4 \%$, respectively, from 1991.2 Over the last two decades, CRC research has lead to better understanding of disease behaviour, resulting in more efficient treatments and higher prevalence of cancer survivors. In spite of radical treatment, approximately $30-50 \%$ of patients will develop recurrent disease of whom only $5-30 \%$ would be considered eligible for further surgery; of those only $3-5 \%$ will be actually cured. ${ }^{3,4}$ In addition, the reported rates of second primary tumours in CRC patients are ranging from $5 \%$ to $10 \% .^{5-10}$ Furthermore, long-term analyses of Scandinavian trials have shown an increased risk of second cancers in the patients treated with pre- operative radiotherapy for rectal cancer in organs within or adjacent to the irradiated volume. ${ }^{11}$

The main aim of post-treatment surveillance after potentially curative treatment of CRC is to improve survival through early detection of polyps and new primaries or recurrent tumours when efficient treatment is possible. ${ }^{12-15}$ Secondary goals are to assess the efficacy of initial treatment, management of long-term post-treatment complications, to offer comprehensive psychologic support and support in disease prevention. ${ }^{16}$

\section{Studies of CRC follow-up strategies}

To define the value of varying levels of follow-up intensity in surveillance programs among CRC survivors, six randomized controlled trials were conducted (Table 1). ${ }^{17-22}$ Two of them have showed a survival benefit from more intensive followup. ${ }^{21,22}$ There was a great variability between the 
TABLE 1. Studies comparing intensive with less intensive follow-up

\begin{tabular}{|c|c|c|c|c|c|c|}
\hline Studies & Year & No & CEA testing & $\begin{array}{l}\text { Liver } \\
\text { imaging }\end{array}$ & $\begin{array}{l}5-y \text { OS IFU } \\
\text { (less IFU) }\end{array}$ & $P$ value \\
\hline Makela17 & 1995 & 106 & Yes & Yes & $59 \quad(54)$ & 0.26 \\
\hline Ohlsson 18 & 1995 & 107 & Yes & No & 75 (67) & 0.50 \\
\hline Kjeldsen 19 & 1997 & 597 & No & No & 68 (70) & 0.48 \\
\hline Schoemaler20 & 1998 & 325 & No & Yes & $76 \quad(70)$ & 0.20 \\
\hline
\end{tabular}

Abbreviations: No = number of patients; OS = overall survival; IFU = intensive follow-up

studies in defining the follow-up. For example, the kind of follow-up that was considered as "intensive" in the study by Makela et al. ${ }^{17}$, was assessed by Shoemaker et al. ${ }^{20}$ as "less intensive". In some of the studies, the sample size was not sufficient to detect survival differences with different surveillance strategies, and some of the studies included patients with stage I disease.

Therefore, some meta-analysis were performed as a systematic approach to identification and abstraction of critical information from different randomised, controlled trials. ${ }^{23}$ Two meta-analyses of five randomised trials identified a survival advantage for the patients followed more intensely as significantly higher incidence of asymptomatic local or systemic recurrence was recognized among the patients monitored closely and, consequentially, reoperation for cure was more frequent in this group. ${ }^{24,25}$ These results were confirmed by another, recently published meta-analysis including six randomised trials on this topic with a significant improvement in survival favouring more intense follow-up (Relative Risk Ratio 0.80; 95\%CI, 0.70 to $0.91 ; p=0.0008)$. A significant improvement in survival was observed only those trials which included CEA testing and/or liver imaging. ${ }^{26}$ Another two meta-analyses (on randomised and nonrandomised trials) concluded that intensive follow-up programmes can improve survival ${ }^{27,28}$, and should be »individualised « according to a person's characteristics. ${ }^{27}$

In an attempt to rationalize CRC follow-up, three prospective multi-institutional randomised trials comparing more intensive with less intensive monitoring are being carried out at the moment: the FACS trial in United Kingdom, the FFCD trial in France and the GILDA trial in Italy. ${ }^{29}$ The GILDA follow-up schemes are presented in Table 2 . The results of these trials are pending.

\section{Potential limitations of follow-up}

Few considerations have to be taken into account when promoting surveillance and there are some limitations to this approach.

First, there is a small risk of adverse events associated with colonoscopy itself or with polipectomy during the follow-up. Only one of the prospective randomised follow-up studies reported these data: two perforations and two gastrointestinal haemorrhages from a total of 731 colonoscopies. ${ }^{20}$

Secondly, frequent visits to physician might be inconvenient to the patients and even harmful due to unnecessary exposition to radiation. ${ }^{30}$ Fear of recurrence or unnecessary stress resulting from false positives results may also have a negative impact on the quality of their lives. False positive results are on average 16 times (0.2-200) more common than true positive results. ${ }^{31}$ On the other hand, reassuring effect of normal test results and psychological support from physician might be beneficial. The data about the effect of follow-up on patients' health-related quality of life (HRQL) are limited and conflicting. While Stiggelbout et al. and Wattchow et al. indicated that HRQL was not improved through follow-up visits, Kjeldsen et al. demonstrated a small but significant increase in HRQL with a more intensive follow up. ${ }^{32-34}$ However, Stiggelbout et al. emphasized that most patients would prefer regular contacts even if they showed no benefit in terms of earlier detection of recurrence. ${ }^{32}$

The third factor to be taken into consideration when promoting surveillance is high cost of such program. A wide variety of follow-up schemes are associated with large differences in costs. Few studies focused on this issue. Virgo et al. reported a 28-fold difference in costs between minimal and 
TABLE 2. GILDA trial for rectal cancer follow-up

\begin{tabular}{|c|c|c|c|c|c|c|c|c|c|c|c|}
\hline & \multicolumn{11}{|c|}{ Months from randomisation } \\
\hline & 4 & 8 & 12 & 16 & 20 & 24 & 30 & 36 & 42 & 48 & 60 \\
\hline \multicolumn{12}{|l|}{ Less intensive } \\
\hline CEA & + & + & + & + & + & + & + & + & + & + & + \\
\hline Proctoscopy & + & & & & & & & & & & \\
\hline Chest X-ray & & & + & & & & & & & & \\
\hline Liver ultrasound & & + & & + & & & & & & & \\
\hline \multicolumn{12}{|l|}{ More intensive } \\
\hline Office visit & + & + & + & + & + & + & + & + & + & + & + \\
\hline Blood tests & + & + & + & + & + & + & + & + & + & + & + \\
\hline Liver ultrasound & + & + & + & + & & + & & + & & + & + \\
\hline Abdominal-pelvic CT & + & & + & & & + & & & & + & \\
\hline
\end{tabular}

Abbreviations: blood tests include complete blood count, liver tests, tumour markers CEA and Ca 19-9.

most extensive 5-year follow-up in USA, ranging from US\$ 910 to US\$26.717. ${ }^{35}$ Audisio et al. calculated the 5-year follow-up costs in Italy as follows: US\$ 3.800 per patient; US\$ 13.580 for each recurrence; US\$ 59.841 for every recurrence treated for cure and US\$ 13.6779 for each cured patient; the difference in costs between minimal and aggressive 5 -year follow-up protocol was US\$ 4.800 per patient. Authors recommended that the programmes should be tailored to the stage and site of primary cancer in order to reduce costs ${ }^{36}$ and that controlled economic studies are required. ${ }^{37}$ The cost-effectiveness analysis of five randomized trials showed that the cost for the intensive follow-up resulted in a net extra cost of US\$ 4.214-4.299 per patient compared with the less intensive follow-up arm. Each life year saved through the intensive follow-up was calculated to cost between US\$ 5.230-5.783.24

When resectability of recurrences was considered, a cost minimization analysis performed by Rodrigues et al. demonstrated that the cost per resectable tumour recurrence was lower in the intensively followed group..$^{38}$ This is a logical conclusion despite the fact that the overall cost of intensive follow up was higher in the intensive strategy group than in less intensive one.

Other authors pointed to the high cost of followup suggesting that it should be transferred to the primary care setting. The arguments were that the specialist care is more intense and that specialists tend to propose more expensive follow-up strategies. $^{39}$

The question remains, who should carry out the follow-up visits. With increasing numbers of CRC survivors, primary care physicians (PCPs) are more and more engaged in CRC follow-up programs. ${ }^{40-42}$ The data from the literature regarding the utility of general versus specialist care in CRC survivors are sparse. In a study by Nissen et al., PCPs reported dissatisfaction with this transfer of care for survivors; they also felt uncertain about the appropriate frequency and duration of surveillance testing for cancer recurrence. ${ }^{43}$ Moreover, in a recently published study by Snyder et al., the authors reported a decreased intensity of cancer-related screening program as oncologists were becoming less involved in survivor care. The survivors followed up by both a PCP and an oncologist were most likely to receive both noncancer-related recommended care and cancer surveillance. ${ }^{42}$ The authors concluded that a shared model of survivorship care should be developed with a clear and detailed description of roles of both sides, $\mathrm{PCP}^{\prime} \mathrm{s}$ and oncologist's, to gain maximal coordination and efficacy. ${ }^{44}$ On the other hand, some data suggest that the survivors followed up by PCP only did not perceive lower qua- 
TABLE 3. Follow-up guidelines of main professional societies

\begin{tabular}{|c|c|c|c|}
\hline $\begin{array}{l}\text { History, } \\
\text { physical exam }\end{array}$ & $\begin{array}{l}\text { Every } 3-6 m \text { for } 3 y \text {, then every } 6 \\
m \text { up to } 5 y\end{array}$ & $\begin{array}{l}\text { Every } 3-6 \mathrm{~m} \text { for } 2 \mathrm{y} \text {, then every } \\
6 \mathrm{~m} \text { up to } 5 \mathrm{y}\end{array}$ & $\begin{array}{l}\text { every } 3-6 \mathrm{~m} \text { for } 3 \mathrm{y} \text {, then every } 6-12 \mathrm{~m} \text { for } 2 \mathrm{y} \\
\text { (colon) every } 6 \mathrm{~m} \text { for } 2 \mathrm{y} \text { (rectal cancer) }\end{array}$ \\
\hline Colonoscopy & at $3 y$, every $5 y$ thereafter & $\begin{array}{l}\text { At } 1 y \text {, then at } 3 y \text {, every } 5 y \\
\text { thereafter }\end{array}$ & $\begin{array}{l}\text { After ly, then every 3y (colon) every } 5 y \text { (rectal } \\
\text { cancer) }\end{array}$ \\
\hline Blood tests & not recommended & not recommended & not recommended \\
\hline CEA & every 3-6m for 3y (stage II and III) & $\begin{array}{l}\text { every } 3-6 \mathrm{~m} \text { for } 2 y \text {, then every } 6 \mathrm{~m} \\
\text { up to } 5 y \text { (staged as T2 or greater) }\end{array}$ & $\begin{array}{l}\text { if initially elevated: every } 3-6 \mathrm{~m} \text { for } 3 y \text {, then } \\
\text { every } 6-12 \mathrm{~m} \text { for } 2 \mathrm{y} \text { (colon) not recommended } \\
\text { (rectal cancer) }\end{array}$ \\
\hline $\begin{array}{l}\text { CT thorax and CT } \\
\text { abdomen }\end{array}$ & $\begin{array}{l}\text { annually for } 3 y \text { for pts with high } \\
\text { risk of recurrence }\end{array}$ & annually for $3-5 y$ for stage $\|$ and III & $\begin{array}{l}\text { Every } 6 \mathrm{~m} \text { for } 3 y \text { for pts with high risk of } \\
\text { recurrence (colon) Not recommended } \\
\text { (rectal cancer) }\end{array}$ \\
\hline $\begin{array}{l}\text { Pelvic CT } \\
\text { (rectal cancer) }\end{array}$ & $\begin{array}{l}\text { negative prognostic features, } \\
\text { especially for not irradiated pts } \\
\text { (no frequency) }\end{array}$ & Not covered & not recommended \\
\hline
\end{tabular}

lity of care ${ }^{40}$, which was also confirmed by others mentioning that no difference was recorded in the rate of recurrence and death as well as time to detection of recurrence in comparison to the patients followed by a surgeon or PCP. 45

Finally, with respect to cost and time consumption of follow-up, it seems reasonable that the surveillance of patients for whom additional therapeutic options when recurrence occurs are available ${ }^{4,46}$, should be more intense. Furthermore, particular attention was paid to determine the subgroups of CRC patients which might benefit the most from follow-up with regard to tumour site or stage. The results of a prospective randomized trial on 259 CRC survivors conducted by Rodrigues-Moranta et al. indicated that the patients with stage II tumours or lesions in the rectum had higher overall survival when followed more intensively than those on less intensive follow-up program. No difference was found between the patients with stage III lesions or lesions located in colon. ${ }^{38}$

\section{Current recommendations and adherence to them by physicians}

Several guidelines have been published on the surveillance of CRC survivors. Follow-up program is recommended by all leading professional societies, e.g. the American Society of Clinical Oncology $(\mathrm{ASCO})^{47}$, National Comprehensive Cancer Network (NCCN) $)^{48,49}$ and European Society Medical Oncology (ESMO). ${ }^{50,51}$ Surveillance protocols include regular outpatient's visits followed by physical examination, CEA monitoring, radiological and endoscopic examinations. It must be stressed that none of diagnostic procedures by itself is sensitive or specific enough to detect the recurrence at early, treatable stage; so, the guidelines recommend different packages of tests.

Although there are differences in frequency, intensity and combinations of investigations as proposed by various programs, some parts of recommendations are similar (Table 3). Monitoring is more intense during the first two to three years after radical treatment, as most of the recurrences 
occur within this period of time. There is a debate when to stop performing individual tests or monitoring the patients as they are an increased lifetime risk of developing recurrent disease or new primary CRC. The guidelines recommend continued, albeit less frequent visits during 3-5 years after therapy. Although local recurrences after adjuvant therapy are less common, irradiated rectal cancer patients may experience late relaps. ${ }^{52,53}$ Many experts believe that follow-up beyond five years is necessary for such patients. ${ }^{54}$

While recommendations concerning colonoscopy in high risk patients are consistent, there is a great variability in the standards of other tests. In ESMO guidelines the routine clinical, laboratory and radiological examinations are not indicated in rectal cancer patients at all. Furthermore, pelvic CT scanning for rectal cancer is recommended only in ASCO guidelines (Table 3).

Due to aggressive therapy, CRC survivors can exhibit late sequel of treatment ${ }^{54-59}$, most common being impaired bowel, voiding, sexual malfunctioning and quality of life impairment, bone fractures after pelvic radiation, oxaliplatin-induced neuropathy and psychosocial distress. Among the three guidelines mentioned only the NCCN ones describe potential late effects of treatment; unfortunately, they include only little information on how to manage the symptoms.

The consequence of lacking uniform guidelines is that the heterogeneity among physicians regarding the use of follow-up tests is serious. For example, a postal survey of all the active members of the American Society of Colon and Rectal Surgeons (ASCRS) undertaken in 1994 found that only 50\% of surgeons who returned the questionnaire adhere to official recommendations. ${ }^{60}$ Twelve years later, Giordano et al. reported that only $30 \%$ of surgeons followed any guidelines. Of these, only $20 \%$ stuck to the national guidelines and $80 \%$ followed local recommendations. ${ }^{61}$

Disparities in follow-up care are also observed when patient's race and age are taken into account. The report from Rolnick et al. highlighted that one of the reasons for poorer survival of black CRC patients in comparison with white patients might be that they have less follow-up surveillances. ${ }^{62} \mathrm{~A}$ study conducted by Cooper et al. in 9.426 patients aged over 65 revealed that less than half of older CRC patients in the US during post-therapy period receive recommended screening for recurrence, indicating that the physician's preferences may influence the choice of testing. ${ }^{63}$

\section{Conclusions}

Follow-up of CRC survivors is a common practice. Intensive surveillance enhances the probability of diagnosing precancerous lesions, recurrences or new primaries at early stage when the existing treatment options could be used with curative intent. Consequentially, comprehensive surveillance program improves the survival and at the same time - as it seems from available data, does not affect the quality of patients' life. On the other hand, the increased costs and time consumption of intensive surveillance limit its utility. Due to limited, and to some extent conflicting data, there are no uniform guidelines for the CRC survivors regarding the frequency of visits and tests to be performed at each visit. Ongoing large prospective multi-institutional randomised trials might elucidate some of the crucial questions and existing dilemmas to establish an adequate surveillance strategy for CRC patients.

\section{Acknowledgement}

The article resumes the lecture given by the author during the second edition of the international course "Oncology for surgeons" in Iasi, Romania on April 14-18, 2009.

\section{References}

1. Cancer incidence in Slovenia 2006. Report no. 48. Ljubljana: Institute of Oncology Ljubljana, Cancer Registry of Republic of Slovenia; 2009.

2. Primic Žakelj M, Zadnik V, Žagar T, Zakotnik B. Survival of cancer patients, diagnosed in 1991-2005 in Slovenia. Ljubljana: Institute of Oncology Ljubljana, Cancer Registry of Republic of Slovenia; 2009.

3. Goldberg RM, Fleming TR, Tangen CM, Moertel CG, Macdonald JS, Haller $D G$, et al. Surgery for recurrent colon cancer: strategies for identifying resectable recurrence and success rates after resection. Ann Intern Med 1998; 129: 27-35.

4. Velenik V. Locally recurrent rectal cancer: treatment options. Radiol Oncol 2009; 43: 144-51.

5. Cali RL, Pitsch RM, Thorson AG, Watson P, Tapia P, Blatchford GJ, et al. Cumulative incidence of metachronous colorectal cancer. Dis Colon Rectum 1993; 36: 388-93.

6. Enblad P, Adami HO, Glimelius B, Krusemo U, Pahlman L. The risk of subsequent primary malignant diseases after cancers of the colon and rectum. A nationwide cohort study. Cancer 1990; 65: 2091-100.

7. Bulow S, Svendsen LB, Mellemgaard A. Metachronous colorectal carcinoma. BrJ Surg 1990; 77: 502-5.

8. Evans HS, Moller H, Robinson D, Lewis CM, Bell CMJ, Hodgson SV. The risk of subsequent primary cancers after colorectal cancer in southeast England. Gut 2001; 50: 647-52

9. Shureiqi I, Coaksley CD, Morris J, Soliman AS, Levin B, Lippman SM: Effect of age on risk of second primary colorectal cancer. J Natl Cancer Inst 2001; 93: 1264-6. 
10. Green RJ, Metlay JP, Propert K, Catalano PJ, Mayer RJ, Haller DG. Surveillance for second primary colorectal cancer after adjuvant chemotherapy: an analysis of Intergroup 0089. Ann Int Med 2002; 136: 261-9.

11. Birgisson H, Píhlman L, Gunnarsson U, Glimelius B. Occurrence of second cancers in patients treated with radiotherapy for rectal cancer. J Clin Oncol 2005; 23: 6126-31.

12. Goldberg RM, Fleming TR, Tangen CM, Moertel CG, Macdonald JS, Haller $D G$, et al. Surgery for recurrent colon cancer: strategies for identifying resectable recurrence and success rates after resection. Eastern Cooperative Oncology Group, the North Central Cancer Treatment Group, and the Southwest Oncology Group. Ann Intern Med 1998; 129: 27-35.

13. Anthony T, Fleming JB, Bieligk SC, Sarosi GA, Kim LT, Gregorcyk SG, et al. Postoperative colorectal cancer surveillance. J Am Coll Surg 2000; 190: 737-49.

14. Korner H, Soreide K, Stokkeland PJ, Soreide JA. Systematic follow-up after curative surgery for colorectal cancer in Norway: a population-based audit of effectiveness, costs, and compliance. J Gastrointest Sur 2005; 9: 320-8.

15. Turk PS, Wanebo HJ. Results of surgical treatment of nonhepatic recurrence of colorectal carcinoma. Cancer 1993; 71(Suppl 12): 4267-77.

16. Perše $\mathrm{M}$, Cerar A. Physical activity and colorectal cancer. [Slovenian]. Zdrav Vestn 2009; 78: 399-405.

17. Makela JT, Laitinen SO, Kairaluoma MI. Five-year follow-up after radical surgery for colorectal cancer. Results of a prospective randomized trial. Arch Surg 1995; 130: 1062-7.

18. Ohlsson B, Breland U, Ekberg $\mathrm{H}$, Graffner $\mathrm{H}$, Trannberg KG. Follow- up after curative surgery for colorectal carcinoma. Randomized comparison with no follow-up. Dis Colon Rectum 1995; 38: 619-26.

19. Kjeldsen BJ, Kronborg $O$, Fenger $C$, Jřrgensen $O D$. A prospective randomized study of follow-up after radical surgery for colorectal cancer. Br J Surg 1997; 84: 666-9.

20. Schoemaker D, Black R, Giles L, Toouli J. Yearly colonoscopy, liver CT, and chest radiography do not influence 5-year survival of colorectal cancer patients. Gastroenterology 1998; 114: 7-14.

21. Pietra N, Sarli L, Costi R, Ouchemi C, Grattarola M, Peracchia A. Role of follow-up in management of local recurrences of colorectal cancer. Dis Colon Rectum 1998, 41: 1127-33.

22. Secco GB, Fardelli R, Gianquinto D, Bonfante P, Baldi E, Ravera G, et al Efficacy and cost of risk-adapted follow up in patients after colorectal cancer surgery: a prospective, randomized and controlled trial. Eur J Surg Oncol 2002, 28: 418-23.

23. Kovač V, Smrdel U. Meta-analyses of clinical trials in patients with non-smal cell lung cancer. Neoplasma 2004; 51: 334-40.

24. Renehan AG, Egger M, Saunders MP, O'Dwyer ST. Impact on survival of intense follow-up after curative resection of colorectal cancer: systematic review and meta-analysis of randomized trials. Brit Med J 2002, 324: 1-8.

25. Jeffery GM, Hickey BE, Hider P. Follow-up strategies for patients treated for non-metastatic colorectal cancer. Cochrane Database Syst Rev 2002; 1: CD002200.

26. Figueredo A, Rumble RB, Maroun J, Earle CC, Cummings B, McLeod R, et al. Follow-up of patients with curatively resected colorectal cancer: a practice guideline. BMC Cancer 2003; 3: 26

27. Bruinvels DJ, Stiggelbout AM, Kievet J, van Houwelingen HC, Habbema JD, van de Velde CJ. Follow-up of patients with colorectal cancer: A metaanalysis. Ann Surg 1994; 219: 174-82.

28. Rosen M, Chan L, Beart RW, Anthone G. Follow-up of colorectal cancer: meta-analysis. Dis Colon Rectum 1998; 41: 1116-26.

29. Grossmanna EM, Johnsona FE, Virgoa KS, Longob WE, Fossatic R. Follow-up of colorectal cancer patients after resection with curative intent-the GILDA trial. Surg Oncol 2004; 13: 119-24.

30. Miklos M, Gajski G, Garaj-Vrhovac V. Usage of the standard and modified comet assay in assessment of DNA damage in human lymphocytes after exposure to ionizing radiation. Radiol Oncol 2009; 43: 97-107.

31. Kievit J. Follow-up of patients with colorectal cancer: numbers needed to test and treat. Eur J Cancer 2002; 38: 986-99.
32. Stiggelbout AM, de Haes JC, Vree R, van der Velde CJ, Brujninckx CM, van Groningen $\mathrm{K}$, et al. Follow-up of colorectal cancer patients: quality of life and attitudes towards follow-up. Br J Cancer 1997; 75: 914-20.

33. Wattchow DA, Weller DP, Esterman A, Pilotto LS, McGorm K, Hammett Z, et al. General practice vs surgical-based follow-up for patients with colon cancer: randomised controlled trial. Br J Cancer 2006; 94: 1116-21.

34. Kjeldsen BJ, Thorsen H, Whalley D, Kronborg O. Influence of follow-up on health-related quality of life after radical surgery for colorectal cancer. Scand J Gastroenterol 1999; 34: 509-15.

35. Virgo KS, Vernava AM, Longo WE, McKirgan LW, Johnson FE. Cost of patient follow-up after potentially curative colorectal cancer treatment. JAMA 1995; 273: 1837-41.

36. Audisio RA, Setti-Carraro P, Segala M, Capko D, Andreoni B, Tiberio G. Follow-up in colorectal cancer patients: a cost-benefit analysis. Ann Surg Oncol 1996; 3: 349-57.

37. Zieren HU, Muller JM. After-care of gastrointestinal malignancies: an evaluation of costs and benefits. Zentralb/ Chir 1996; 121: 167-76.

38. Rodríguez-Moranta F, Saló J, Arcusa A, Boadas J, Piñol V, Bessa X, et al. Postoperative surveillance in patients with colorectal cancer who have undergone curative resection: A prospective, multicenter, randomized, controlled trial. J Clinl Oncol 2006; 24: 386-93.

39. Earle CC, Grunfeld E, Cripps MC, Stern HS. Cancer physicians' attitudes toward colorectal cancer follow-up. Ann Oncol 2003; 14: 400-5.

40. Haggstrom D, Arora N, Oakley-Girvan I. Primary and subspecialty care models of follow-up care delivery among colorectal cancer survivors [Abstract]. $J$ Clin Oncol 2008; 26(Suppl 1): Abstract 6540.

41. Snyder C, Earle C, Herbert R, Neville BA, Blackford AL, Frick KD. Trends in follow-up and preventive care for colorectal cancer survivors. J Gen Intern Med 2008; 23: 254-9.

42. Snyder CF, Earle CC, Herbert RJ, Neville BA, Blackford AL, Frick KD. Preventive care for colorectal cancer survivors: a 5-year longitudinal study. J Clin Oncol 2008; 26:1073-9.

43. Nissen MJ, Beran MS, Lee MW, Mehta SR, Pine DA, Swenson KK. Views of primary care physicians on follow-up care of cancer patients. Fam Med 2007; 39: 477-82.

44. Institute of Medicine. From cancer patient to cancer survivor: lost in transition. Washington, DC: National Academy Press; 2005.

45. Wattchow DA, Weller DP, Esterman A, Pilotto LS, McGorm K, Hammett Z, et al. General practice vs surgical-based follow- up for patients with colon cancer: randomised controlled trial. Br J Cancer 2006, 94: 1116-21.

46. Ocvirk J. Advances in the treatment of metastatic colorectal carcinoma. Radiol Oncol 2009; 43: 1-8.

47. Desch CE, Benson AB 3rd, Somerfield MR, Flynn PJ, Krause C, Loprinzi CL, et al. Colorectal cancer surveillance. 2005 update of an American Society of Clinical Oncology practice guideline. J Clin Oncol 2005; 23: 8512-9.

48. Engstrom PF, Arnoletti JP, Benson AB 3rd, Chen YJ, Choti MA, Cooper HS, et al. NCCN Clinical Practice Guidelines in Oncology: rectal cancer. J Natl Compr Canc Netw 2009; 7: 838-81.

49. Engstrom PF, Arnoletti JP, Benson AB 3rd, Chen YJ, Choti MA, Cooper HS, et al. NCCN Clinical Practice Guidelines in Oncology: colon cancer. J Nat/ Compr Canc Netw 2009; 7: 778-831.

50. Glimelius B, Oliveira J. Rectal cancer: ESMO clinical recommendations for diagnosis, treatment and follow-up. Ann Oncol 2009; 20 (Suppl 4): iv54-6.

51. Van Cutsem EJ, Oliveira J. Primary colon cancer: ESMO clinical recommendations for diagnosis, adjuvant treatment and follow-up. Ann Oncol 2009; 20 (Suppl 4): iv49-50.

52. Peeters KC, Marijnen CA, Nagtegaal ID, Kranenbarg EK, Putter H, Wiggers T, et al. The TME trial after a median follow-up of 6 years: increased local control but no survival benefit in irradiated patients with resectable rectal carcinoma. Ann Surg 2007; 246: 693-701.

53. Collette L, Bosset JF, den Dulk M, Nguyen F, Mineur L, Maingon P, et al. Patients with curative resection of cT3-4 rectal cancer after preoperative radiotherapy or radiochemotherapy: does anybody benefit from adjuvant fluorouracil-based chemotherapy? A trial of the Europea. J Clin Oncol 2007; 25: 4379-86. 
54. Van Cutsem E, Dicato M, Haustermans K, Arber N, Bosset JF, Cunningham D, et al. The diagnosis and management of rectal cancer: expert discussion and recommendations derived from 9th World Congress on Gastrointestinal Cancer, Barcelona 2007. Ann Oncol 2008; 19 (Suppl 6): vi1-8.

55. Velenik V, Oblak I, Anderluh F. Quality of life in patients after combined modality treatment of rectal cancer: Report of a prospective phase II study. Radiol Oncol 2008; 42: 207-14.

56. Schneider EC, Malin JL, Kahn KL, Ko CY, Adams J, Epstein AM. Surviving colorectal cancer: patient-reported symptoms 4 years after diagnosis. Cancer 2007; 110: 2075-82.

57. Sprangers MAG, Taal BG, Aaronson NK, Velde A. Quality of life in colorectal cancer: stoma vs.nonstoma patients. Dis Colon Rectum 1995; 38: 361-9.

58. Kalso E, Tasmuth T, Neuvanen PJ. Amitriptyline effectivelly relieves neuropatic pain following treatment of breast cancer. Pain 1996; 64: 293-302.

59. Baxter NN, Habermann EB, Tepper JE, Durham SB, Virnig BA. Risk of pelvic fractures in older women following pelvic irradiation. JAMA 2005; 294: 2587-93.

60. Vernava AM 3rd, Longo WE, Virgo KS, Coplin MA, Wade TP, Johnson FE. Current follow-up strategies after resection of colon cancer. Results of a survey of members of the American Society of Colon and Rectal Surgeons. Dis Colon Rectum 1994; 37: 573-83.

61. Giordano P, Efron J, Vernava AM III, Weiss EG, Nogueras JJ, Wexner SD Strategies of follow-up for colorectal cancer: a survey of the American Society of Colon and Rectal Surgeons. Tech Coloproctol 2006; 10: 199-207.

62. Rolnick S, Hensley Alfors S, Kucera GP, Fortman K, Ulcickas Yood M Jankowski $\mathrm{M}$, et al. Racial and age differences in colon examination surveillance following a diagnosis of colorectal cancer. J Natl Caner Inst Monogr 2005; 96-101.

63. Cooper GS, Kou DT, Reynolds HL Jr. Receipt of guideline-recommended follow-up in older colorectal cancer survivors: a population-based analysis. Cancer 2008; 113: 2029-37. 